\title{
Oral Health and Autism Spectrum Disorders: A Unique Collaboration between Dentistry and Occupational Therapy
}

\author{
Dominique H. Como $^{1, *}$, Leah I. Stein Duker ${ }^{1}{ }^{\circledR}$, José C. Polido ${ }^{2}$ and Sharon A. Cermak $^{1}$ \\ 1 Mrs. T.H. Chan Division of Occupational Science and Occupational Therapy, Herman Ostrow School of \\ Dentistry, University of Southern California, Los Angeles, CA 90089, USA; 1stein@chan.usc.edu (L.I.S.D.); \\ cermak@chan.usc.edu (S.A.C.) \\ 2 Children's Hospital Los Angeles and Herman Ostrow School of Dentistry, University of Southern California, \\ Los Angeles, CA 90089, USA; JPolido@chla.usc.edu \\ * Correspondence: dcomo@usc.edu
}

Citation: Como, D.H.; Stein Duker, L.I.; Polido, J.C.; Cermak, S.A. Oral Health and Autism Spectrum Disorders: A Unique Collaboration between Dentistry and Occupational Therapy. Int. J. Environ. Res. Public Health 2021, 18, 135.

https://dx.doi.org/10.3390/ ijerph18010135

Received: 4 November 2020 Accepted: 23 December 2020 Published: 27 December 2020

Publisher's Note: MDPI stays neutral with regard to jurisdictional claims in published maps and institutional affiliations.

Copyright: (c) 2020 by the authors. Licensee MDPI, Basel, Switzerland. This article is an open access article distributed under the terms and conditions of the Creative Commons Attribution (CC BY) license (https: / / creativecommons.org/ licenses/by/4.0/).

\begin{abstract}
Children with autism spectrum disorders (ASD) are at risk for oral health disparities With the dramatic rise in ASD prevalence to 1 in 54 children, it is likely that an increasing number of dental practitioners will encounter or be asked to treat children with ASD. This paper reviews explanations related to the increasing prevalence of ASD, provides reasons why children with ASD are at increased risk for poor oral health, and discusses unique interprofessional collaborations between dental practitioners and occupational therapists. Occupational therapists and dentists can work together to plan modifications to the dental environment or adapt dental protocols to reduce some of the barriers encountered by those with ASD, provide desensitization strategies before the clinic visit, or help a child with emotional regulation during clinical treatments.
\end{abstract}

Keywords: autism spectrum disorder; dentistry; interprofessional collaboration; occupational therapy; oral health

\section{Introduction}

Children with special health care needs (CSHCNs), such as autism spectrum disorders (ASD), are at greater risk for experiencing oral health disparities than the general population [1-3]. The prevalence of ASD has risen dramatically to 1 in 54 children [4]. Given the high prevalence of ASD, it is likely that an increasing number of dental practitioners will encounter children with ASD in their practice or will be asked to treat children with ASD. In this paper we review reasons related to the increasing prevalence of ASD, provide reasons why children with ASD are at increased risk for poor oral health, and discuss unique collaborations among occupational therapists and dentists that may enhance care for this population.

\section{The Rise of ASD}

ASD is a neurodevelopmental disorder characterized by deficits in initiating social interactions, maintaining social communication, and a range of restricted repetitive behaviors (RRBs), interests, and activities [5]. Deficits in social interactions and communication include challenges in social-emotional reciprocity, non-verbal communication, and establishing, or even understanding, relationships. RRBs include repetitive mannerisms (hand flapping, rocking), stereotyped behaviors, unusually strong interests, or perseverations. Sensory hypo- or hyper-reactivity to sensory stimuli recently has been added to this category [5]. As the name suggests, ASD is a continuum from mild to severe [6-8].

Historically, autism was considered extremely rare. One of the earliest reports, based on behavior questionnaires, interviews, and case records, estimated prevalence to be about 4.5 per 10,000 [9]. However, in the last half-century, there has been a dramatic increase in autism diagnoses. The estimated prevalence of ASD in the United States has 
been monitored by the Centers for Disease Control and Prevention (CDC) Autism and Developmental Disabilities Monitoring Network (ADDM) since 2000, with increases in rates of ASD with each surveillance. In 2000, the prevalence of ASD was 1 in 150. In 2006, it was 1 in 110, and in 2012 it rose to 1 in 68. In the most recent report, published in 2020 based on the 2016 surveillance year, the rate increased to 1 in 54 [4,10].

Research is exploring several theories to explain the changes in prevalence in ASD over time, including diagnostic-related changes (e.g., changes to the criteria for diagnosis, advancements in diagnostic tools, new policies regarding early diagnosis/intervention) [5,11-28] and increased focus on gender, racial and ethnic disparities [29-39]. Other aspects include increased recognition of the role of genetics [40-45], prenatal influences [46-49], changes in stigma [50-53], parental age [48,54,55], and pollution and other environmental factors [44-47,49,56-60]. Likely, a combination of factors rather than one single factor contributes to the etiology of ASD.

\section{Oral Health and Autism Spectrum Disorders}

Oral health care is a major public health concern and has been identified as a Leading Health Indicator, which are topic areas determined to be of high-priority for action [61]. Given the high prevalence of ASD, it is likely that an increasing number of dental practitioners will encounter children with ASD in their practice or will be asked to treat children with ASD. Therefore, it is important to consider how the symptomatology and severity of an ASD diagnosis may impact health and how interprofessional approaches might improve care for this population.

\section{Risk Factors for Oral Health Challenges}

Research has identified a number of factors that contribute to poor oral health in children with ASD, including difficulty tolerating home and professional oral care, sensory processing differences, uncooperative behaviors, communication impairments, as well as challenges finding and accessing professional oral care services.

Children with ASD experience challenges with oral care both at home and at the dentist. One study reported that as few as 50\% of children with ASD brushed their teeth the recommended twice per day, and up to $61 \%$ of parents with children with ASD report that toothbrushing is difficult $[62,63]$. This may be attributed in part to the fact that up to $90 \%$ of children with ASD experience sensory processing differences [64]. In the home, the child may experience difficulty with the taste or texture of toothpaste or the tactile sensation of the toothbrush bristles in the mouth. In the dental office, there may be challenges with the taste or smell of prophylaxis paste or fluoride, the dentist touching their face, bright lights shining in the child's eyes, the high-pitched sound of dental equipment, and unusual smells $[62,65]$. These types of sensory sensitivities have been associated with the uncooperative behaviors of children with ASD in the dental office $[65,66]$.

Uncooperative behaviors (e.g., crying, screaming, verbal protests, unwillingness to comply) also may influence the success of the visit. These refusals of treatment require dental practitioners to consider alternative methods, such as the use of restraint, general anesthesia, or even the refusal of the dentist to treat the patient [67]. In a study that analyzed data from a national survey of general dentists, dentists reported that the patient's behavior was a high level barrier to their willingness to treat CSHCNs [68]. The American Academy of Pediatric Dentistry recommends a number of basic behavior guidance techniques to help a child, including Tell-Show-Do, voice control, nonverbal communication, and positive reinforcement [67]; however, these traditional strategies may not be sufficient for children with ASD.

Impairments in communication may make it difficult for children to express their needs and discomfort. Research suggests that children with ASD who demonstrate impairments in communication often have more unmet health needs than those without communication difficulties $[69,70]$. Similarly, ASD-related behaviors can serve as a barrier to care in the dental clinic. For example, some children with ASD exhibit repetitive or 
stereotypic movements, such as rocking or hand flapping, both of which might hinder dental treatment.

In addition, many families of children with ASD experience a difficult time locating dentists willing to treat their child [62,71]. In fact, only $40 \%$ of general dental practitioners stated that they would work with children with ASD [72]. This could be due to a multitude of reasons, one of which is the dental practitioners' perceived ability to work with the population. In a survey of general dentists in the United States, the majority of the respondents reported that their dental education had not prepared them well to work with special needs populations [72-74]. Internationally, similar results were found in a survey of dentists in Saudi Arabia $(n=108)$, with over $75 \%$ of the respondents indicating that additional education was required to feel comfortable managing patients with special health care needs [75]. Those dentists who reported feeling more prepared were more likely to "set up their practice so that special needs patients could be treated" [72] (p. 1114). Similar results were found in a study that examined the attitudes and behaviors of general and pediatric dentists' in relation to their patients with ASD; the more prepared the dentists' felt, the more likely they were to provide care for this population [76]. Without specialized training, general dental practitioners may not be confident in their abilities to address the very specific needs of the ASD population [73,74,77].

Furthermore, working with children with ASD may require additional effort. A survey of Special Care Dentistry Association Members reported that dental practitioners used an average of approximately six accommodations to facilitate dental visits and address difficulties (i.e., communication, routine, social interactions) presented by some children with ASD [78]. The majority of dental practitioners also reported that the financial compensation was inadequate when treating patients with ASD due to the additional time required to prepare for and complete a visit [78]. Dentists are often only able to bill for services rendered (i.e., oral exam), not the associated costs of additional staff, lengthy treatment time, or extra desensitization visits. Current funding practices de-incentivize practitioners from serving this population.

Due to the high prevalence of the above-mentioned challenges, it is especially important that treating dentists be aware of the possibility of encountering sensory processing differences and uncooperative behaviors, as well as the available strategies to combat them.

\section{Leveraging the Dental Strategic Initiative to Benefit CSHCNs}

Education and continued training are important components in the development of a workforce prepared to serve diverse, vulnerable populations. The Advancing Dental Education in the 21st Century project recommends interprofessional collaboration as a means of strengthening the educational foundation of dental practitioners [79]. Knowing the difficulties that some individuals with special health care needs encounter when seeking oral care in the dental clinic and the increasing prevalence of ASD in the United States and abroad, it is important to explore the potential impact these proposed educational and training strategies will have on preparing dental practitioners to serve populations with special needs.

\subsection{Suggestions to Address ASD Population Needs \\ 4.1.1. Patient-Centered Model of Care}

Although the Advancing Dental Education in the 21st Century project was not specifically designed to address the demands of CSHCNs, such as ASD, many of the suggestions are meaningful options in addressing challenges those with ASD encounter. One of the proposed strategies is to move to a patient-centered model of care. The recommendation is to "increase the time that [dental] students spend in community settings, such as clinics, hospitals and dental groups" and "operate some dental school clinics as patient-centered delivery systems" [79] (p. eS9). This transition to a patient-centered model will expose more general dental practitioners to the diversity of patients they will likely encounter in their practice and provide increased opportunities for hands-on learning experiences, 
both of which are important when treating children with ASD. Additionally, operating in a patient-centered delivery system would ensure that other health professionals are practicing toward the same primary goal of providing comprehensive patient care [79].

CSHCNs often have complex medical conditions that require integrated care. The medical home model was originally introduced by the American Academy of Pediatrics (AAP) to provide care that facilitates participation between patient, family, clinicians, and medical staff [80]. Team-based care has been shown to be efficacious in prevention, health maintenance, and illness management [81]. In a nationally representative sample, researchers found that care in a patient-centered medical home was significantly associated with higher parent-reported health care quality for CSHCNs, with an increased likelihood of accessing prescriptions and other office-based services [82].

\subsubsection{Integrated Educational Programming}

Interdisciplinary work does not have to be limited to clinical practice. The benefits of integrating multiple healthcare fields' educational programming are also noted in the recommendations. The proposed methods of integration include enhancing "dental curricula and support[ing] the integration of oral and systemic health content in the curricula of all health professions programs" [79] (p. eS11). One benefit of implementing an integrative approach to oral health for those with ASD is that it will better prepare dental practitioners to collaborate effectively with other health care professionals. Given the impact of oral care on overall health, it is important that this interdisciplinary collaboration occurs.

\subsubsection{Interdisciplinary Collaboration}

As previously stated, education and continued training are important components in the development of a workforce that is prepared to work with diverse, largely underserved populations. Interprofessional collaboration may be one way to strengthen the educational foundation of dental practitioners in the clinic. Interdisciplinary collaboration with other fields, such as Occupational Therapy, Behavioral Therapy, Psychology, Special Education, Computer Science, and Informatics, provide different perspectives on care and strategies to increase the probability of success for children with ASD in the dental clinic. These strategies range from providing education about sensory sensitivities and creating a sensory-friendly environment; assisting with the development and use of visual supports and social stories, and/or use of video/virtual technology. These strategies all have, at least, preliminary support for their use for children with ASD [66,83-93].

Sensory-friendly environments can modify the sensory experiences encountered by children with ASD, either adding (e.g., weighted blankets, calming music) or removing (e.g., bright lights, loud noises) sensory stimuli encountered during dental care or in the waiting room to decrease stress and anxiety $[66,85,86,94]$. Strategies incorporating visual supports may improve cooperation and participation; these may include visual schedules, which are visual representations of a task broken down and sequenced into step-by-step directions, and visual clocks, which are particularly helpful in aiding the child to keep track of time $[66,90]$. Video tutorials have been developed to improve children with ASD's toothbrushing technique by providing virtual modeling of target behaviors [91]. Videomodeling of a child successfully undergoing a dental visit and watching a favorite movie as a distractor are possible interventions to improve fear and uncooperative behaviors during dental visits [74]. Interventions based on high-tech alternative and augmentative communication (AAC) techniques have also been found to improve self-care activities and cooperation during dental treatments when utilized as part of a digital media support system as well as to inform the development of personalized information and communication technologies (ICT) app [92,93].

Overall, numerous strategies to enhance oral care for children with ASD, often from interdisciplinary teams, have demonstrated success for children with ASD. However, future research is needed to determine which interventions are best suited for which children, especially due to the heterogenous nature of the symptomology for children with ASD 
and how it may present in the dental clinic. This highlights the need for interprofessional collaboration, which will benefit all fields involved in improving the lives of children with ASD.

\section{Interdisciplinary Collaboration: A Focus on Occupational Therapy}

One specific interdisciplinary collaboration that may be beneficial to improve oral care for children with ASD involves integrating the field of occupational therapy into dentistry. Occupational therapy uses everyday life activities to enhance and enable participation in what people need to do, what they want to do, and what they are expected to do $[95,96]$. One of the main focuses of occupational therapy is activities of daily living (including oral care), and it is one of the most frequently used services among those with ASD [97]. Occupational therapists (OTs) often work with children with ASD in school, in their home, and in community settings where they evaluate factors (e.g., sensory, motor, cognitive, social, and communication) that affect individuals' skills and participation in everyday life activities [98]. As such, OTs are adept at identifying strengths and challenges while adapting and modifying activities to facilitate participation.

Collaborating with OTs who regularly provide services to children with ASD may facilitate dental practitioners' understanding of the heterogeneity and symptomology of the ASD population, as well as provide possible strategies to improve oral care to this population. Occupational therapy is a discipline that can aid the child through dental care either in the clinic during treatment (i.e., emotional regulation-the ability to monitor and modulate emotions) or before the clinic visit (i.e., in-home desensitization strategies, social stories). OTs can work with dentists to plan modifications to the dental environment or adapt dental protocols to reduce some of the barriers encountered by those with ASD [66,99].

An example of interdisciplinary collaboration is currently underway at the University of Southern California (USC) between the Chan Division of Occupational Science and Occupational Therapy, the Herman Ostrow School of Dentistry at USC, Children's Hospital Los Angeles (CHLA) Division of Dentistry, and the mental health program at the USC University Center for Excellence in Developmental Disabilities (UCEDD) based at CHLA. As part of a research study funded by the National Institutes of Health's National Institute of Dental and Craniofacial Therapy, a multidisciplinary team led by OTs has designed a sensory adapted dental environment that modifies the lighting, sounds, and tactile sensations experienced at the dental clinic to reduce anxiety and increase cooperative behaviors in children with ASD [94]. In addition to the environmental adaptations, the OTs developed a social narrative ("social story") using real-life photographs of a happy child in the dental office where the child with ASD would be receiving care (e.g., waiting room, hallway, private room) to illustrate what would happen during the visit to the Dental Clinic. The parent was asked to read the story to their child several times before their dental visit to help them prepare for the activities of the visit. This is important because many children with ASD become distressed with new, novel, or unpredictable situations, and social narratives provide the child with behavioral guidance stated in positive terms, such as, "When the dentist looks at my teeth, I will keep my mouth open" [100]. In implementing this protocol, occupational therapy doctoral students work alongside pediatric dental residents in the CHLA Division of Dentistry, where an exchange of knowledge continuously occurs. USC occupational therapists, CHLA dentists, and UCEDD psychologists have collaboratively published several manuscripts and presented at dental, psychology, and occupational therapy, and interdisciplinary autism conferences, e.g., $[94,101]$.

Other collaborative activities at USC include inviting OTs to participate in professional proceedings and grand rounds. For the last ten years, OTs have provided seminars to USC pediatric dental residents, describing the particular challenges children with ASD experience in relation to oral care and strategies that can be utilized by dental practitioners to improve care for this population. 


\section{Conclusions}

The prevalence of ASD is increasing, and many individuals with ASD experience oral care challenges related to difficulties in communication, sensory sensitivities, and uncooperative behaviors. As such, there is an increasing need for dentists who are trained to work with this population.

The dental field is currently re-examining ways to improve educational programming, ultimately impacting future service delivery. This is an ideal time to address these issues. One of the most promising approaches is to improve interprofessional collaborations, which will aid in the development of a more competent workforce who are willing and able to work with diverse populations. Collaborating with OTs may provide ASD-specific strategies that dental practitioners' can add to their existing toolbox to serve the needs of the ASD population and provide client-centered strategies dental practitioners can use to best serve those with ASD best. Ultimately, the more confident dental practitioners feel in their knowledge and abilities, the more likely they are to include individuals with ASD in their practice.

Author Contributions: The responsibility of D.H.C. was to conceptualize, analyze, investigate, and write; L.I.S.D. was to supervise, analyze, investigate and write; J.C.P. was to analyze, investigate, and write; S.A.C. was to conceptualize, supervise, analyze, and write. All authors have read and agreed to the published version of the manuscript.

Funding: This study was supported in part by the National Institute of Dental and Craniofacial Research (U01DE024978; 3U01DE024978-04S1; F31DE030006) and the University of Southern California, Mrs. T.H. Chan Division of Occupational Science and Occupational Therapy. The second author was additionally supported by the National Center for Medical Rehabilitation Research (K12 HD005929).

Conflicts of Interest: The authors declare no conflict of interest. The funders had no role in the design of the study; in the collection, analyses, or interpretation of data; in the writing of the manuscript, or in the decision to publish the results.

\section{References}

1. Murthy, V. Oral health in America, 2000 to present: Progress made, but challenges remain. Public Health Rep. 2014, 131, $224-225$. [CrossRef] [PubMed]

2. Fisher-Owens, S.; Isong, I.A.; Soobader, M.; Gansky, S.A.; Weintraub, J.A.; Platt, L.J.; Newacheck, P.W. An examination of racial/ethnic disparities in children's oral health in the United States. J. Public Health Dent. 2013, 73, 166-174. [CrossRef] [PubMed]

3. Koritsas, S.; Iacono, T. Secondary conditions in people with developmental disability. Am. J. Intellect. Dev. Disabil. 2011, 116, 36-47. [CrossRef] [PubMed]

4. Maenner, M.J.; Shaw, K.A.; Baio, J.; Washington, A.; Patrick, M.; DiRienzo, M.; Christensen, D.L.; Wiggins, L.D.; Pettygrove, S.; Andrews, J.G.; et al. Prevalence of autism spectrum disorder among children aged 8 years-autism and developmental disabilities monitoring network, 11 Sites, United States, 2016. MMWR Surveill. Summ. 2020, 69, 1-12. [CrossRef]

5. American Psychiatric Association. Diagnostic and Statistical Manual of Mental Disorders, 5th ed.; American Psychiatric Association: Arlington, VA, USA, 2013.

6. Lord, C.; Elsabbagh, M.; Baird, G.; Veenstra-Vanderweele, J. Autism spectrum disorder. Lancet 2018, 392, 508-520. [CrossRef]

7. Masi, A.; De Mayo, M.; Glozier, N.; Guastella, A. An overview of autism spectrum disorder, heterogeneity and treatment options. Neurosci. Bull. 2017, 33, 183-193. [CrossRef]

8. Solomon, M.; Iosif, A.M.; Reinhardt, V.P.; Libero, L.E.; Nordahl, C.W.; Ozonoff, S.; Rogers, S.J.; Amaral, D.G. What will my child's future hold? Phenotypes of intellectual development in 2-8-year-olds with autism spectrum disorder. Autism Res. 2018, 11, 121-132. [CrossRef]

9. Lotter, V. Epidemiology of autistic conditions in young children. Soc. Psychiatry 1966, 1, 124-135. [CrossRef]

10. Centers for Disease Control and Prevention. Autism Spectrum Disorders: Data and Statistics (Prevalence). Autism and Developmental Disabilities Monitoring Network. Available online: https:/ /www.cdc.gov/ncbddd/autism/data.html (accessed on 26 March 2020).

11. Feinstein, A. A History of Autism Conversations with the Pioneers; Wiley-Blackwell: Chichester, UK, 2010.

12. Kita, Y.; Hosokawa, T. History of Autism Spectrum Disorders: Historical controversy over diagnosis. Hist. Controv. Diagn. 2011, 59, 147-166.

13. American Psychiatric Association. Diagnostic and Statistical Manual of Mental Disorders, 1st ed.; American Psychiatric Association: Washington, DC, USA, 1952. 
14. American Psychiatric Association. Diagnostic and Statistical Manual of Mental Disorders, 2nd ed.; American Psychiatric Association: Washington, DC, USA, 1968.

15. American Psychiatric Association. Diagnostic and Statistical Manual of Mental Disorders, 3rd ed.; American Psychiatric Association: Washington, DC, USA, 1980.

16. American Psychiatric Association. Diagnostic and Statistical Manual of Mental Disorders, 4th ed.; American Psychiatric Association: Washington, DC, USA, 1994.

17. Lord, C.; Luyster, R.J.; Gotham, K.; Guthrie, W. (ADOS-2) Manual (Part. II): Toddler Module. In Autism Diagnostic Observation Schedule, 2nd ed.; Western Psychological Services: Torrance, CA, USA, 2012.

18. Lord, C.; Rutter, M.; DiLavore, P.C.; Risi, S.; Gotham, K.; Bishop, S.L. (ADOS-2) Manual (Part. I): Modules 1-4. In Autism Diagnostic Observation Schedule, 2nd ed.; Western Psychological Services: Torrance, CA, USA, 2012.

19. Bieleninik, L.; Posserud, M.-B.; Geretsegger, M.; Thompson, G.; Elefant, C.; Gold, C. Tracing the temporal stability of autism spectrum diagnosis and severity as measured by the autism diagnostic observation schedule: A systematic review and metaanalysis. PLoS ONE 2017, 12, e0183160. [CrossRef]

20. Falkmer, T.; Anderson, K.; Falkmer, M.; Horlin, C. Diagnostic procedures in autism spectrum disorders: A systematic literature review. Eur. Child. Adolesc. Psychiatry 2013, 22, 329-340. [CrossRef] [PubMed]

21. Ozonoff, S.; Goodlin-Jones, B.L.; Solomon, M. Evidence-based assessment of autism spectrum disorders in children and adolescents. J. Clin. Child. Adolesc. Psychol. 2005, 34, 523-540. [CrossRef] [PubMed]

22. Blacher, J.; Cohen, S.R.; Azad, G. In the eye of the beholder: Reports of autism symptoms by anglo and latino mothers. Res. Autism Spectr. Disord. 2014, 8, 1648-1656. [CrossRef]

23. Zwaigenbaum, L.; Bauman, M.L.; Fein, D.; Pierce, K.; Buie, T.; Davis, P.A.; Newschaffer, C.; Robins, D.L.; Wetherby, A.; Choueiri, R.; et al. Early screening of autism spectrum disorder: Recommendations for practice and research. Pediatrics 2015, 136, S41-S59. [CrossRef] [PubMed]

24. American Academy of Pediatrics. Clinical report: Identification and evaluation of children with Autism Spectrum Disorders. Pediatrics 2007, 120, 1183-1215. [CrossRef] [PubMed]

25. Healthy Children. Public Health Minute: Early Identification of ASD. Available online: https://www.healthychildren.org/ English/health-issues/conditions/Autism/Pages/Public-Health-Minute-Early-Identification-of-ASD.aspx (accessed on 23 November 2018).

26. Turner-Brown, L.; Baranek, G.; Reznick, J.; Watson, L.; Crais, E. The First Year Inventory: A longitudinal follow-up of 12-month-old to 3-year-old children. Autism 2012, 17, 527-540. [CrossRef] [PubMed]

27. Robins, D.L.; Casagrande, K.; Barton, M.; Chen, C.M.; Dumont-Mathieu, T.; Fein, D. Validation of the modified checklist for autism in toddlers, revised with follow- up (M-CHAT-R/F). Pediatrics 2014, 133, 37-45. [CrossRef]

28. Matson, J.L.; Kozlowski, A.M. The increasing prevalence of autism spectrum disorders. Res. Autism Spectr. Disord. 2011, 5, 418-425. [CrossRef]

29. Centers for Disease Control and Prevention. Community Report of Autism 2020. Autism and Developmental Disabilities Monitoring Network. Available online: https:/ / www.cdc.gov/ncbddd/autism/addm-community-report/key-findings.html (accessed on 26 March 2020).

30. Interagency Autism Coordinating Committee. IACC Strategic Plan for Autism Spectrum Disorder. Available online: https: / /iacc.hhs.gov/publications/strategic-plan/2017/ (accessed on 20 June 2019).

31. Dworzynski, K.; Ronald, A.; Bolton, P.; Happe, F. How different are girls and boys above and below the diagnostic threshold for autism spectrum disorders? J. Am. Acad. Child. Adolesc. Psychiatry 2012, 51, 788-797. [CrossRef]

32. Halladay, A.K.; Bishop, S.; Constantino, J.N.; Daniels, A.M.; Koenig, K.; Palmer, K.; Messinger, D.; Pelphrey, K.; Sanders, S.J.; Singer, A.T.; et al. Sex and gender differences in autism spectrum disorder: Summarizing evidence gaps and identifying emerging areas of priority. Mol. Autism 2015, 6, 36-41. [CrossRef]

33. Happe, F.; Frith, U. Annual research review: Looking back to look forward-changes in the concept of autism and implications for future research. J. Child. Psychol. Psychiatry 2020, 61, 218-232. [CrossRef] [PubMed]

34. Bernier, R.; Mao, A.; Yen, J. Psychopathology, families, and culture: Autism. Child Adolesc. Psychiatr. Clin. N. Am. 2010, 19, 855-867. [CrossRef] [PubMed]

35. Harrison, A.J.; Long, K.A.; Tommet, D.; Jones, R.N. Examining the role of race, ethnicity, and gender on social and behavioral ratings within the Autism Diagnostic Observation Schedule. J. Autism Dev. Disord. 2017, 47, 2770-2782. [CrossRef] [PubMed]

36. Mandell, D.; Wiggins, L.; Carpenter, L.; Daniels, J.; DiGuiseppi, C.; Durkin, M.; Giarelli, E.; Morrier, M.J.; Nicholas, J.S.; PintoMartin, J.A.; et al. Racial/ethnic disparities in the identification of children with autism spectrum disorders. Am. J. Public Health 2009, 99, 493-498. [CrossRef] [PubMed]

37. Liptak, G.S.; Benzoni, L.B.; Mruzek, D.W.; Nolan, K.W.; Thingvoll, M.A.; Wade, C.M.; Fryer, G.E. Disparities in diagnosis and access to health services for children with autism: Data from the National Survey of Children's Health. J. Dev. Behav. Pediatr. 2008, 29, 152-160. [CrossRef] [PubMed]

38. Lopez, K.; Reed, J.; Magaña, S. Associations among family burden, optimism, services received and unmet need within families of children with ASD. Child. Youth. Serv. Rev. 2019, 98, 105-112. [CrossRef]

39. Zuckerman, K.; Sinche, B.; Mejia, A.; Cobian, M.; Becker, T.; Nicolaidis, C. Latino parents' perspectives on barriers to autism diagnosis. Acad. Pediatr. 2014, 14, 301-308. [CrossRef] 
40. Murdoch, J.D.; State, M.W. Recent developments in the genetics of autism spectrum disorders. Curr. Opin. Genet. Dev. 2013, 23, 301-315. [CrossRef]

41. Yoo, H. Genetics of autism spectrum disorder: Current status and possible clinical applications. Exp. Neurobiol. 2015, 24, 257-272. [CrossRef]

42. Centers for Disease Control and Prevention. What is Autism Spectrum Disorder? Available online: https://www.cdc.gov/ ncbddd/autism/facts.html\#ref (accessed on 26 March 2020).

43. Li, Y.; Qiu, S.; Zhong, W.; Li, Y.; Liu, Y.; Cheng, Y.; Liu, Y. Association between DCC polymorphisms and susceptibility to autism spectrum disorder. J. Autism Dev. Disord. 2020, 50, 3800-3809. [CrossRef]

44. Bai, D.; Yip, B.H.K.; Windham, G.C.; Sourander, A.; Francis, R.; Yoffe, R.; Glasson, E.; Mahjani, B.; Suominen, A.; Leonard, H.; et al. Association of genetic and environmental factors with Autism in a 5-country cohort. JAMA Psychiatry 2019, 76, 1035-1043. [CrossRef] [PubMed]

45. Rylaarsdam, L.; Guemez-Gamboa, A. Genetic causes and modifiers of autism spectrum disorder. Front. Cell Neurosci. 2019, 13, 385-400. [CrossRef] [PubMed]

46. Lyall, K.; Croen, L.; Daniels, J.; Fallin, M.D.; Ladd-Acosta, C.; Lee, B.K.; Park, B.Y.; Snyder, N.W.; Schendel, D.; Volk, H. The changing epidemiology of Autism Spectrum Disorders. Annu. Rev. Public Health 2017, 38, 81-102. [CrossRef] [PubMed]

47. Modabbernia, A.; Velthorst, E.; Reichenberg, A. Environmental risk factors for autism: An evidence-based review of systematic reviews and meta-analyses. Mol. Autism. 2017, 8, 1-16. [CrossRef] [PubMed]

48. Pew Research Center. They're Waiting Longer but U.S. Women Today More Likely to Have Children than a Decade Ago. Available online: https: / www.pewsocialtrends.org/2018/01/18/theyre-waiting-longer-but-u-s-women-today-more-likelyto-have-children-than-a-decade-ago/\#fnref-24248-1 (accessed on 23 November 2018).

49. World Health Organization. Preterm Birth. Available online: https://www.who.int/news-room/fact-sheets/detail/pretermbirth (accessed on 23 November 2018).

50. Bettelheim, B. The Empty Fortress: Infantile Autism and the Birth of the Self; Free Press: New York, NY, USA, 1967.

51. Kanner, L. Early infantile autism. J. Pediatr. 1944, 25, 211-217. [CrossRef]

52. Hodge, N. Reflections on diagnosing autism spectrum disorders. Disabil. Soc. 2005, 20, 345-349. [CrossRef]

53. Russell, G.; Norwich, B. Dilemmas, diagnosis and de-stigmatization: Parental perspectives on the diagnosis of autism spectrum disorders. Clin. Child. Psychol. Psychiatry 2012, 17, 229-245. [CrossRef]

54. Durkin, M.S.; Maenner, M.J.; Newschaffer, C.J.; Lee, L.-C.; Cunniff, C.M.; Daniels, J.L.; Kirby, R.S.; Leavitt, L.; Miller, L.; Zahorodny, W.; et al. Advanced parental age and the risk of autism spectrum disorder. Am. J. Epidemiol. 2008, 168, 1268-1276. [CrossRef]

55. Lee, B.K.; McGrath, J.J. Advancing parental age and autism: Multifactorial pathways. Trends Mol. Med. 2015, 21, 118-125. [CrossRef]

56. Roberts, A.L.; Lyall, K.; Hart, J.E.; Laden, F.; Just, A.C.; Bobb, J.F.; Koenen, K.C.; Ascherio, A.; Weisskopf, M.G. Perinatal air pollutant exposures and autism spectrum disorder in the children of nurses' health study II participants. Environ. Health Perspect 2013, 121, 978-984. [CrossRef]

57. Volk, H.E.; Lurmann, F.; Penfold, B.; Hertz-Picciotto, I.; McConnell, R. Traffic-related air pollution, particulate matter, and autism. Arch. Gen. Psychiatry 2013, 70, 71-77. [CrossRef] [PubMed]

58. Dickerson, A.S.; Rahbar, M.H.; Bakian, A.V.; Harrington, R.A.; Pettygrove, S.; Kirby, R.S.; Durkin, M.S.; Han, I.; Moye, L.A.; Pearson, D.A.; et al. Autism spectrum disorder prevalence and associations with air concentrations of lead, mercury, and arsenic. Environ. Monit. Assess. 2016, 188, 407-423. [CrossRef] [PubMed]

59. U.S. Environmental Protection Agency. National Air Quality: Status and Trends of Key Air Pollutant. Available online: https: / / www.epa.gov / air-trends (accessed on 5 November 2019).

60. Srikantha, P.; Mohajeri, M.H. The possible role of the microbiota-gut-brain axis in autism spectrum disorder. Int. J. Mol. Sci. 2019, 20, 2115. [CrossRef] [PubMed]

61. U.S. Department of Health and Human Services. Healthy People 2020: Oral Health. Available online: https://www.healthypeople. gov /2020/topics-objectives/topic/oral-health (accessed on 25 January 2017).

62. Stein, L.I.; Polido, J.C.; Lopez Najera, S.O.; Cermak, S.A. Oral care experiences and challenges in children with autism spectrum disorders. Pediatr. Dent. 2012, 34, 387-391.

63. Marshall, J.; Sheller, B.; Mancl, L. Caries-risk assessment and caries status of children with autism. Pediatr. Dent. 2010, 32, 69-75.

64. Marco, E.J.; Hinkley, L.B.; Hill, S.S.; Nagarajan, S.S. Sensory processing in autism: A review of neurophysiologic findings. Pediatr. Res. 2011, 69, 48R-54R. [CrossRef]

65. Stein, L.I.; Polido, J.C.; Cermak, S.A. Oral care and sensory over-responsivity in children with autism spectrum disorders. Pediatr. Dent. 2013, 35, 230-235.

66. Stein Duker, L.I. Adapting Oral Care Protocols to Support Children with Sensory Sensitivities: Occupational Therapy and Dentistry. In Dental Care for Children with Special Needs: A Clinical Guide; Nelson, T., de Bord, J.R., Eds.; Springer: Cham, Switzerland, 2019; pp. 77-98.

67. American Academy of Pediatric Dentistry. Behavior Guidance for the Pediatric Dental Patient. Available online: https://www. aapd.org/research/oral-health-policies--recommendations/behavior-guidance-for-the-pediatric-dental-patient/ (accessed on 23 November 2018). 
68. Casamassino, P.S.; Seale, N.S.; Ruehs, K. General dentists' perceptions of educational and treatment issues affecting access to care for children with special health care needs. J. Dent. Educ. 2004, 68, 23-28. [CrossRef]

69. Marshall, J.; Sheller, B.; Williams, B.; Mancl, L.; Cowan, C. Cooperation predictors for dental patients with autism. Pediatr. Dent. 2007, 29, 369-376.

70. McKinney, C.M.; Nelson, T.; Scott, J.M.; Heaton, L.J.; Vaughn, M.G.; Lewis, C.W. Predictors of unmet dental need in children with autism spectrum disorder: Results from a national sample. Acad. Pediatr. 2014, 14, 624-631. [CrossRef]

71. Alumran, A.; Almulhim, L.; Almohim, B.; Bakodah, S.; Aldossary, H.; Alakrawi, Z. Preparedness and willingness of dental care providers to treat patients with special needs. Clin. Cosmet. Investig. Derm. 2018, 10, 624-631. [CrossRef] [PubMed]

72. Dao, L.P.; Zwetchkenbaum, S.; Inglehart, M.R. General dentists and special needs patients: Does dental education matter? J. Dent. Educ. 2005, 69, 1107-1115. [CrossRef] [PubMed]

73. Inglehart, M.R.; Schneider, B.K.; Bauer, P.A.; Dharia, M.M.; McDonald, N.J. Providing care for underserved patients: Endodontic residents', faculty members', and endodontists' educational experiences and professional attitudes and behavior. J. Dent. Educ. 2014, 78, 735-744. [CrossRef] [PubMed]

74. Isong, I.A.; Rao, S.R.; Holifield, C.; Iannuzzi, D.; Hanson, E.; Ware, J.; Nelson, L.P. Addressing dental fear in children with autism spectrum disoredres: A randomized controlled pilot study using electronic screen media. Clin. Pediatr. 2014, 53, $230-237$. [CrossRef] [PubMed]

75. Alamoudi, N.M.; Almushayt, A.S.; el Derwi, D.A.; Mirdad, L.H.; el-Ashiry, E.A. Dentists' perception of the care of patients with special health care needs in Jeddah, Saudi Arabia. J. Oral Hyg. Health 2017, 5, 226-233. [CrossRef]

76. Weil, T.N.; Inglehart, M.R. Dentist education and dentist attitudes and behavior concerning patients with autism. J. Dent. Educ. 2010, 74, 1294-1307. [CrossRef] [PubMed]

77. Jones, D.M.; Miller, S.R. Effectiveness of an educational module on dental hygiene students' attitudes towards persons with disabilities. J. Dent. Hyg 2018, 92, 27-34.

78. Weil, T.N.; Bagramian, R.A.; Inglehart, M.R. Treating patients with autism spectrum disorder-SCDA members' attitudes and behavior. Spec. Care Dent. 2011, 31, 8-17. [CrossRef]

79. Formicola, A.J.; Bailit, H.J.; Weintraub, J.A.; Fried, J.L.; Polverini, P.J. Advancing dental education in the 21st century: Phase 2 report on strategic analysis and recommendations. J. Dent. Educ. 2018, 82, eS1-eS32. [CrossRef]

80. American Academy of Pediatrics. Engaging Patients and Families: What is a Medical Home? Available online: https://www.aap. org/en-us/professional-resources/practice-transformation/managing-patients/Pages/what-is-medical-home.aspx (accessed on 4 November 2020).

81. Katkin, J.P.; Kressly, S.J.; Edwards, A.R.; Perrin, J.M.; Kraft, C.A.; Richerson, J.E.; Tieder, J.S.; Wall, L. Guiding principles for team-based pediatric care. Pediatrics 2017, 140, e20171489. [CrossRef]

82. Lin, C.; Romley, J.A.; Carlin, C. The relationship between the patient-centered medical homes, healthcare expenditures, and quality of care among children with special health care needs. Matern Child. Health J. 2018, 22, 1751-1760. [CrossRef] [PubMed]

83. Kuhaneck, H.M.; Chisholm, E.C. Improving dental visits for individuals with autism spectrum disorders through an understanding of sensory processing. Spec. Care Dent. 2012, 32, 229-233. [CrossRef] [PubMed]

84. Datt, C.; Travers, M.; Odell, C. Improving the hospital experience for young people with autism. Arch. Dis. Child 2017, 102, A20.

85. Chen, H.-Y.; Yang, H.; Chi, H.-J.; Chen, H.-M. Physiological effects of deep touch pressure on anxiety alleviation: The weighted blanket approach. J. Med. Bio. Eng. 2012, 33, 463-470. [CrossRef]

86. Hong, E.Y.; Cermak, S.A.; Stein Duker, L.I. Occupational therapists' distinct value in creating a sensory-friendly waiting room. Sis. Q. Pract. Connect. 2018, 3, 11-13.

87. Autism Speaks. Dental Guide. Available online: https://www.autismspeaks.org/sites/default/files/2018-08/Dental\%20Guide. pdf (accessed on 26 March 2020).

88. Marion, I.W.; Nelson, T.M.; Sheller, B.; McKinney, C.M.; Scott, J.M. Dental stories for children with autism. Spec. Care Dent. 2016, 36, 181-186. [CrossRef]

89. Elmore, J.L.; Bruhn, A.M.; Bobzien, J.L. Interventions for the reduction of dental anxiety and corresponding behavioral deficits in children with Autism Spectrum Disorders. J. Dent. Hyg. 2016, 90, 111-120.

90. Mah, J.W.T.; Tsang, P. Visual schedule system in dental care patients with Autism: A pilot study. Int. J. Clin. Pediatr. Dent. 2016, 5, 393-399. [CrossRef]

91. Popple, B.; Wall, C.; Flink, L.; Powell, K.; Discepolo, K.; Keck, D.; Madamtzi, M.; Volkmar, F.; Shic, F. Brief report: Remotely delivered video modeling for improving oral hygiene in children with ASD: A pilot study. J. Autism Dev. Disord. 2016, 46, 2791-2796. [CrossRef]

92. Narzisi, A.; Bondioli, M.; Pardossi, F.; Billeci, L.; Buzzi, M.C.; Buzzi, M.; Pinzino, M.; Senette, C.; Semucci, V.; Tonacci, A.; et al. "Mom let's go to the dentist!" Preliminary feasibility of a tailored dental intervention for children with autism spectrum disorder in the Italian public health service. Brain Sci. 2020, 10, 444. [CrossRef]

93. Grewal, N.; Sethi, T.; Grewal, S. Widening horizons through alternative and augmentative communication systems for managing children with special care needs in a pediatric dental setup. Spec. Care Dent. 2015, 35, 114-119. [CrossRef] [PubMed]

94. Cermak, S.A.; Stein Duker, L.I.; Williams, M.E.; Dawson, M.E.; Lane, C.J.; Polido, J.C. Sensory adapted dental environments to enhance oral care for children with autism spectrum disorders: A randomized controlled pilot study. J. Autism Dev. Disord. 2015, 45, 2876-2888. [CrossRef] [PubMed] 
95. American Occupational Therapy Association. Occupational therapy practice framework: Domain and process. Am. J. Occup. 2014, 68, S1-S48. [CrossRef]

96. World Federation of Occupational Therapy. Definition of Occupational Therapy. 2012. Available online: http://www.wfot.org/ AboutUs/AboutOccupationalTherapy/DefinitionofOccupationalTherapy.aspx (accessed on 26 March 2020).

97. Interactive Autism Network. Ian research findings: Occupational therapy for autism. Available online: https://iancommunity. org/cs/ian_treatment_reports/occupational_therapy (accessed on 2 November 2019).

98. American Occupational Therapy Association [AOTA]. Occupational Therapy's Role with Autism. Available online: https://www. aota.org/ \{\}/media/Corporate/Files / AboutOT/Professionals/WhatIsOT/CY / Fact-Sheets / Autism\%20fact\%20sheet.pdf (accessed on 5 November 2019).

99. Stein Duker, L.I.; Florindez, L.I.; Como, D.H.; Tran, C.F.; Henwood, B.F.; Polido, J.C.; Cermak, S.A. Strategies for success: A qualitative study of caregiver and dentist approaches to improving oral care for children with autism. Pediatr. Dent. 2019, 41, 4E-12E.

100. Gray, C. The New Social Story Book, 15th ed.; Future Horizons: Arlington, TX, USA, 2015.

101. Stein, L.; Lane, C.J.; Williams, M.E.; Dawson, M.E.; Polido, J.C.; Cermak, S.A. Physiological and behavioral stress and anxiety in children with autism spectrum disorder during routine oral care. BioMed Res. Int. 2014, 2014, 1-10. [CrossRef] 